\title{
Money Laundering in the Chinese Art Market and its Solutions
}

\author{
Fanyu Zhou, Ralf Sensel \\ College of Humanities and Sciences of Northeast Normal University Changchun, China 130117
}

Keywords: art market; corruption; money laundering; bribery

\begin{abstract}
The Chinese art market has been flourishing at an incredibly high speed in the past decade. Interviews show that money laundering plays a major part in the rapid development of the Chinese art market. This paper tries to figure out how money is laundered through art transaction. Finally, some recommendations are offered to deal with the problems associated with the Chinese art market.
\end{abstract}

\section{Introduction}

In the past decade of years, the Chinese art and antique market flourished as never before, seeing its peak in 2011( see table 1). Although the transaction turnover has been declining in the following years, figure 1 shows that China still holds the top position in the world art auction market in 2016. Furthermore, the increase is historically unparalleled all over the world. What has contributed to the apparent explosion in the Chinese art market? It was reported by China's art market monitor Artron ${ }^{(1)}$ that "2010 and 2011 are not only the peak years" of the Chinese art market trade volume, but also the "year of the bubble". Although the auction turnover is huge, with a great number of sky-high prices, "void trade and false business constitute a big proportion.,"[1]

Table 1. The turnover in China’s Art auction market.

\begin{tabular}{|l|l|l|l|l|l|l|l|}
\hline $\begin{array}{l}\text { Year } \\
\text { (spring) }\end{array}$ & 2011 & 2012 & 2013 & 2014 & 2015 & 2016 & 2017 \\
\hline $\begin{array}{l}\text { Turnover } \\
\text { (million } \\
\text { RMB) }\end{array}$ & $42,505.55$ & $26,272.04$ & $25,756.87$ & $30,669.55$ & $22,772.92$ & $23,972.67$ & $25,550.58$ \\
\hline
\end{tabular}

Source: http://amma.artron.net/report.php

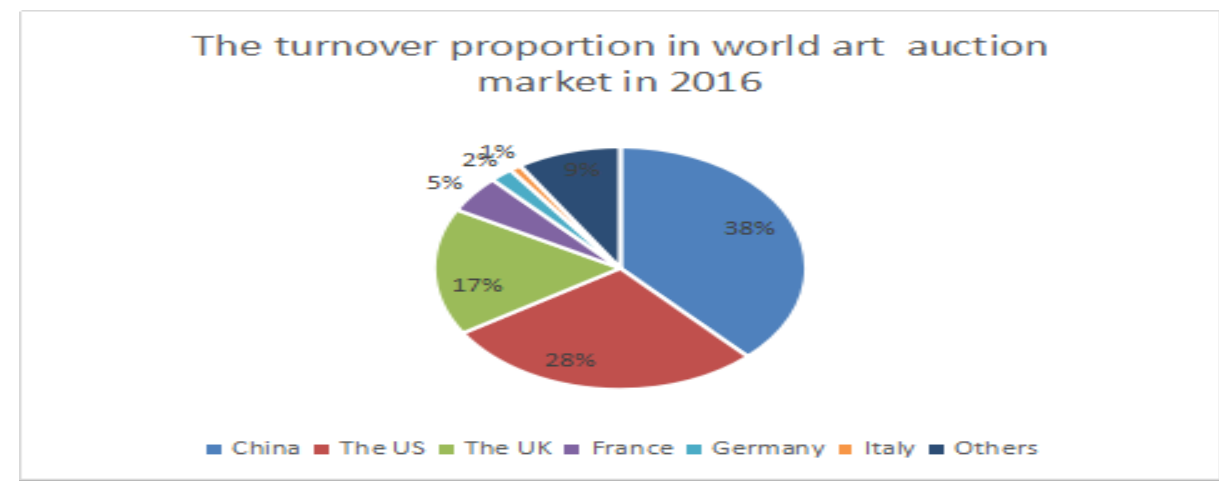

Figure 1. The turnover proportion in world art auction market.

\footnotetext{
(1) The Art Market Monitor of Artron(the AMMA) is the first art market research center in China, and its research are acclaimed as the "weathervane" for investors. AMMA is the only source of data about the Chinese art industry for mainstream media and art institutions in China and other countries, and offers important reference for art collectors, investors and enthusiasts. Its research services is based on the Artron Chinese Artworks Database, recording over 4,300,000 Chinese artworks auction results from over 900 auction houses since 1993.
} 
Source: http://amma.artron.net/report.php

Lifting the veil off the flourishing art market in China, we can see corruption, bribery and money laundering. Xiao Ping, a famous artist and former Nanking Museum Appraisal Consultant said that "in medium and small auction companies, $80 \%$ of the works of art are fake." [2]

This is a contradictory situation since several works of art are dubious or even evidently fake, but managed to be sold at a ridiculously high price. It is ridiculous for a fake to be sold at hundreds of millions of RMB.

Works of art are perfect means to launder dirty money. No one involved in the money laundering transaction will care about whether it is genuine or fake. Chinese art market is mixed with a big number of fakes. Quite a few but far from all fake transactions have been reported. No matter fake or genuine, both can make big money, which leads to the flourishing Chinese art market.

In the auction market, the problem of money laundering is even more prominent. The buyers can not accomplish money laundering without the assistance of the auction companies. The fake works of art has to be appraised and evaluated at a high price by the auction company before sold at an even higher price. Apart from fake works of art, there are false transaction, black box operation, and irresponsible expert appraisal. All these misconducts pave the way for money laundering.

\section{How is the money laundered in the art market?}

This paper only focuses on the alternative ways to bribe and accept bribery through works of art.

A government official in power buys a fake piece of works of art, and entrusts an auction company to sell it. The auction company gives it an inflated evaluation, then the person who wants to bribe him buys it at an incredibly high price. The transaction is completely based on mutual assent and freedom and looks totally legal. No one care about whether the works of art is fake or not. The buyer's real intention is to give money to the government official.

This is the opposite procedure to the above. A person buys a genuine antique vase at a high price. He wants to give it to a government official but it is illegal, then he put the vase on a shelf in an art shop. The government official accidentally buys it at a low price. By this the seller reaches his aim to bribe the official.

If a government official has huge amount of gray income, and in order to make it look legal, he needs the help of third party who specializes in money laundering. He spends some money to buy some fine arts, and then the third party will hype the prices to hundreds of times more. In two or three years, the official sells the pictures by an auction company, the pictures will bring him millions of earnings. In order to maximize the earnings by laundering money, the price of the washed subject will be hyped to hundreds of times more, that is one reason why the Chinese works of art and antiques market has been growing explosively

A senior executive of a state-owned enterprise can set up a museum under the enterprise. He can use the state capital to buy some pictures at high price. The price difference between the pictures' real price and the actual price is put into the senior executive's own pocket.

Some arts stores offer one-stop service to give presents to officials, whereby they make high imitated works of art to bribers who give the art to officials who will have no burden to accept because the art store will purchase the art back. Of course the payment comes from the bribers.

These are only some typical means of laundering money through works of art. There must be some more secluded alternative means which are hard to be found.

\section{The victims of money laundering in art market}

The direct victim of money laundering in the art market is the public--- the individual investors in the art and antique market. The big bubble and the apparent prosperous illusion gives the public a misconception that Chinese art market is extremely promising, which misleads them to make a wrong investment decision. According to a questionnaire made by the authors, the top three 
ordinary people's' means of investment is real estate, antiques and art, financial securities and funds. As is known to all that financial securities and funds are risky, so people will be very wary when they enter the securities market. Since 2014, the downturn in Chinese housing market pushes the public to invest in art market. Our media orient the public that works of art and antiques can help avoid financial risks. Nowadays, more and more people know that antiques and works of art have been appreciating hundreds of times; many people start to try their luck here, many without knowing what is happening behind the prosperous market. Some people put their savings of the whole life into a piece of art; however, it is not easy to be sold at a high price that it is supposed to be. People are perplexed that a similar piece of art was reported to be sold at an incredibly high price, but why their works of art can not be sold at a similar price. They cannot see the connection between money laundering and art business, and make investment in art blindly, whose destiny is being locked up in their works of art.

The Chinese art market is in a crazy state, filled with fakes and bubbles. Chinese art market turnover is number one all over the world since 2012, but we have to know there is more to those numbers than what we see. The Chinese art market is riddled with forgeries, money laundering, bid-rigging and fraud. In this market, a lot of incredible news is exposed. Some are even described as ridiculous as "joke". A considerable amount of the buying is artificial, which is called "show bidding" in the auction business. Whatismore, there is no appraisal system in the art market. There is no authority to price the works of art. It has been reported by China Central Television that quite a few appraisers would offer genuine certificates for fakes if you pay them money and would prove the age for the antiques as the owner's requirement. The point is they would not be liable for their false appraisal. It is absurd that the price is fixed by speculators. Most people in the Chinese art market are speculators as opposed to investors. Investors will have problems with fakes, but speculators don't care as much. The main purchasers of art are businessman and officials. A very limited room is left for real lovers of art to transact in a healthy market.

\section{Recommendations}

In auction market, the works of art should be priced by authoritative appraisers who should be responsible for their appraising report. If they give false appraising, their appraising license must be revoked and they can not work in art field for life. They should be given a severe punishment for malpractice.

At present, China's Anti-money laundering law only requires financial institutions and designated institutions to report large value and suspicious transactions. The other institutions that have connections with the art market should be supervised. "Auctions should be held publicly, and journalist should be present to report so that auctions can not be made secretly."[3]“Large-value" transactions should be defined by number. The Auction Law of China has the confidential provision which hepls the secret under-the-table transactions. It is suggested that this confidential provision be modified.

In order to prevent the works of art of absurdly high price from occurring frequently, heavy taxation on them might be an effective measure. Ladder taxation is a reasonable mode. The higher the price is, the more taxes should be levied.

\section{Conclusion}

Lifted the veil of its prosperity, Chinese art market is really unhealthy. Money laundering has ruined the Chinese art market which shows a morbid development at appalling speed. This paper reveals some examples for how money is laundered in the art market. What we need to do is to cut the connection between corruption and money laundering with art market. First, establish an authoritative appraising system and appraiser-liable principle to remove high-value fakes from the art market. Second, the scope of suspicious transaction report should be enlarged from financial institutes to art market. Third, the two parties to art transaction should pay tax based on the value of the subject. 


\section{References}

[1] http://amma.artron.net/report.php

[2] http://jyfart.com/forum.php?mod=viewthread\&tid=17049\&extra=\&page=6

[3] Fanyu Zhou. What is behind the prosperous art market in China? International Conference on Physical Education and Society Management. 2015.12. 